\title{
Attitudes and Behaviors of Gastroenterology Specialists Toward Sedation Practices in Endoscopy Units in Turkey: Is Anesthesia Mandatory?
}

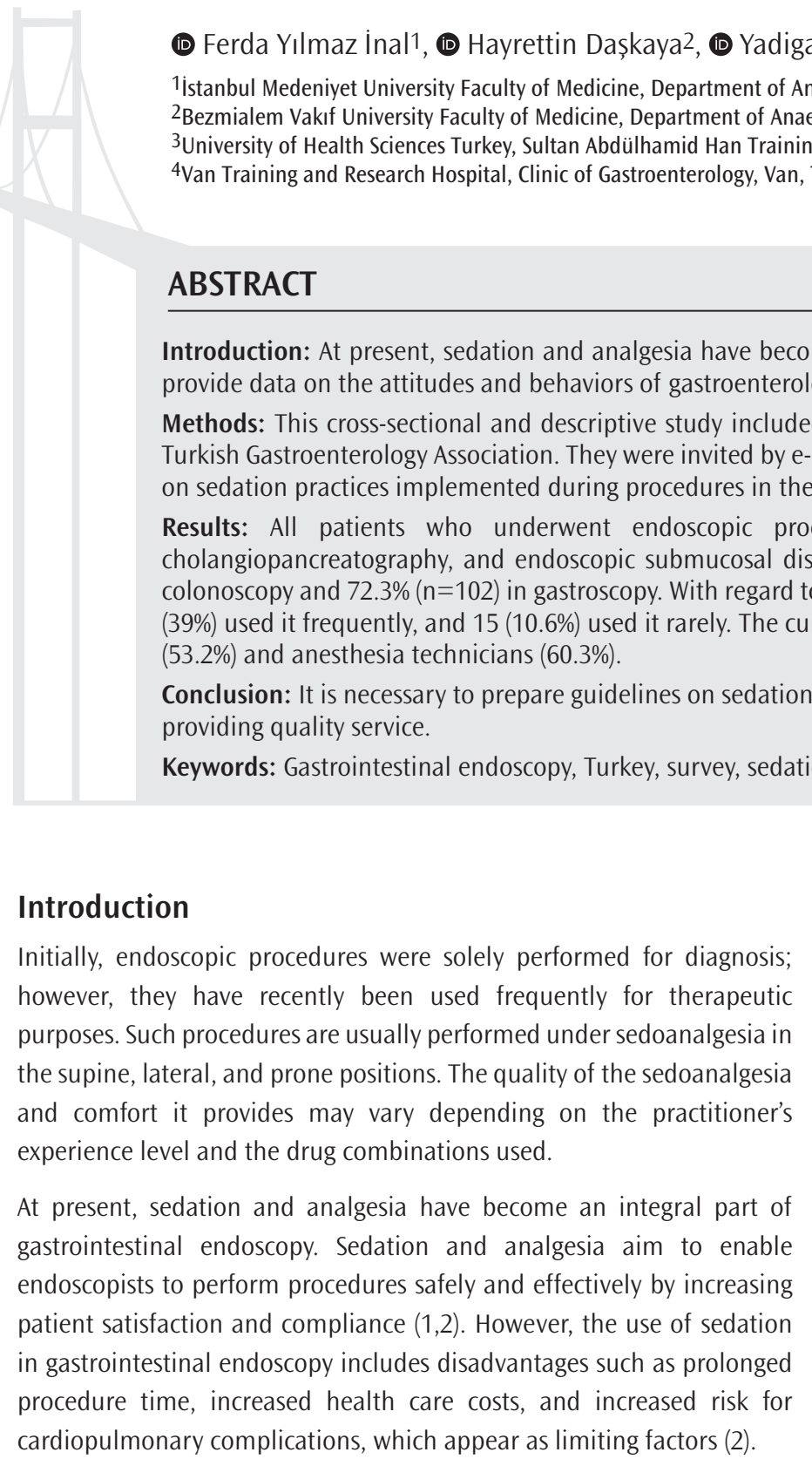

Although various sedation and analgesia techniques are used for gastrointestinal endoscopy procedures, the gold standard is still debated. It is recommended to adapt sedation for each patient according to the clinical risk assessment and type of the planned procedure (3). In some countries, the use of some sedative/analgesic agents is limited to anesthesiologists. There is still ongoing debate about who should be responsible for the use of propofol for sedation. While some studies have reported that propofol can be used safely by an endoscopist for healthy individuals, other studies have disclosed that it can only be used by anesthesiologists trained in the administration of general anesthesia $(4,5)$. Previous studies on sedation models adopted by endoscopists have demonstrated that patient-monitoring practices, such as sedation rates, preferred sedation regimens, and routine use of pulse-oximetry, vary worldwide (6-12).

This study was orally presented at the $51^{\text {th }}$ National Turkish Anesthesiology and Reanimation Congress (October 25 , 2017), Antalya, Turkey.

Address for Correspondence: Ferda Yılmaz İnal MD, İstanbul Medeniyet University Faculty of Medicine, Department

Received: 15.12 .2021 of Anaesthesiology and Reanimation, İstanbul, Turkey Phone: +90 5058207650 E-mail: ferdayilmazinal@hotmail.com ORCID ID: orcid.org/0000-0001-6323-1410

Cite this article as: Yılmaz Inal F, Dașkaya H, Yılmaz Y, Kayar Y. Attitudes and Behaviors of Gastroenterology Specialists Toward Sedation Practices in Endoscopy Units in Turkey: Is Anesthesia Mandatory?. İstanbul Med J 2022; 23(1): 20-8. 
Research on endoscopic sedation is important in understanding "where we stand" and planning future strategies. Many national survey studies have been conducted worldwide on endoscopic sedation (6-13). These studies are also highly useful in evaluating the implementation of sedation guidelines in clinical practice (14). However, to the best of our knowledge, no domestic study has been conducted on endoscopic sedation and monitoring practices during gastrointestinal endoscopy in Turkey. Thus, this study aimed to provide data on the attitudes and behaviors of gastroenterology specialists toward sedation practices in endoscopy units in Turkey.

\section{Methods}

\section{Study Design}

Ethical approval for the study was obtained from Bezmialem Vakıf University Faculty of Medicine Clinical Research Ethics Committee (approval number: 21/30, date: 18.11.2015) and registered on clinicaltrials.gov (identifier: NCT03540238).

\section{Study Protocol}

This was a cross-sectional and descriptive study. A total of 744 gastroenterology specialists, who are members of the Turkish Gastroenterology Association, were invited via e-mail to participate in the study. Feedback was received from 141 of the 744 gastroenterology specialists who were sent the questionnaire. The responses were statistically analyzed.

The questionnaire consisted of 18 items on sedation use during procedures in the endoscopy unit (Appendix A). Survey questions were related to demographics, types of endoscopic procedures, anesthesia methods, anesthetic agents, monitoring methods, anesthesia team members, pre-anesthetic examination and consent forms, recovery unit, complications, and interventions during sedation.

\section{Statistical Analysis}

All statistical analyses were performed using the SPSS 22.0 software package (IBM Corp., Armonk, NY, USA). The sample size was calculated with around 20 individuals falling into each category of questions under the survey. Descriptive statistics of the obtained data were calculated as numbers and \% frequencies and presented in Tables. The FisherFreeman-Halton test was used to analyze the change in the quality and/ or type of people in the anesthesia team according to various factors. A p-value of $<0.05$ was considered significant.

\section{Results}

\section{Demographic Characteristics}

Of the 744 gastroenterology specialists invited to complete the questionnaire, 141 (18.95\%) participated in the study. Analysis of the demographic characteristics of the participants demonstrated a higher rate of university practice hospital employees and young gastroenterologists who responded to our survey call (Table 1).

Anesthesia Method, Anesthetic Agents, Endoscopic Procedure, and Patient Characteristics

All respondents (100\%) used sedation practices in endoscopy units. All patients who underwent endoscopic procedures, such as endoscopic ultrasound, endoscopic retrograde cholangiopancreatography and endoscopic submucosal dissection, received sedation, and the sedation rate was $97.9 \%(n=138)$ in colonoscopies and $72.3 \%(n=102)$ in gastroscopies. With regard to the frequency of sedation use, $33(23.4 \%)$ used sedation for all patients, 55 (39\%) used it frequently, and $15(10.6 \%)$ used it rarely.

Practitioners did not use sedation in $86(61 \%)$ patients who refused sedation, 74 (52.5\%) patients with other diseases (cardiac, pulmonary, renal, etc.), 28 (19.9\%) elderly patients, and 6 (4.3\%) patients with anxiety (Table 2).

Among anesthesia methods, conscious sedation was used by $75.9 \%$, deep sedation by $73 \%$, general anesthesia by $14.2 \%$, and local pharyngeal anesthesia by $65.2 \%$ of the respondents (Table 2 ).

The most commonly used anesthetic agent was midazolam (92.2\%), followed by propofol (75.2\%), fentanyl (23.4\%), ketamine (9.9\%), and remifentanil (5.7\%) (Table 2).

Endoscopy Unit, Monitoring Methods, Oxygen Administration, Sedation Recovery Unit, and Preoperative Evaluation

Oxygen supply (100\%), aspirator (98\%), emergency trolley (91.5\%), and monitor (90.8\%) were available in all endoscopy units at a high rate.

Nasal oxygen was routinely administered to each patient (53.9\%), and peripheral oxygen saturation was monitored (97.2\%). Sedation recovery was achieved in a separate recovery unit (57.4\%).

Table 1. Respondents' demographic characteristics

\begin{tabular}{|c|c|c|}
\hline \multicolumn{2}{|c|}{ Demographic characteristics $(n=141)$} & n (\%) \\
\hline \multirow{3}{*}{ Age group (year) } & $30-49$ & $111(78.7)$ \\
\hline & $50-64$ & $29(20.6)$ \\
\hline & $\geq 65$ & $1(0.7)$ \\
\hline \multirow{2}{*}{ Gender } & Male & $102(72.3)$ \\
\hline & Female & $39(27.7)$ \\
\hline \multirow{4}{*}{ Length of experience (years) } & $0-9$ & 78 (55.7) \\
\hline & $10-19$ & $44(31.4)$ \\
\hline & $20-29$ & $16(11.4)$ \\
\hline & $\geq 30$ & $2(1.4)$ \\
\hline \multirow{4}{*}{ Type of hospital } & University & $75(53.2)$ \\
\hline & Training and research & $30(21.3)$ \\
\hline & State & 15 (10.6) \\
\hline & Private & $21(14.9)$ \\
\hline \multirow{7}{*}{ Region } & Marmara & $76(53.9)$ \\
\hline & Aegean & $10(7.1)$ \\
\hline & Central Anatolia & $23(16.3)$ \\
\hline & Black Sea & $7(5.0)$ \\
\hline & Mediterranean & $11(7.8)$ \\
\hline & Eastern Anatolian & $9(6.4)$ \\
\hline & Southeast & $5(3.5)$ \\
\hline \multirow{3}{*}{ Hospital size (number of beds) } & $<300$ (small) & $32(22.7)$ \\
\hline & 301-500 (medium) & $22(15.6)$ \\
\hline & >501 (big) & 87 (61.7) \\
\hline
\end{tabular}


Moreover, 66\% performed pre-anesthetic evaluation before the procedure $(n=93)$, and $87.2 \%$ routinely received written consent for sedation $(n=123)$.

\section{Anesthesia Team}

The current anesthesia team in endoscopy units consisted of anesthesiologists (53.2\%) and anesthesia technicians (60.3\%). However, there was an increasing trend in endoscopists' preferences toward the presence of an anesthesiologist (86.5\%) and anesthesia technician (81.6\%), whereas a decrease was observed in the preference rates for nurses and other health personnel.

Anesthesia-Related Complications, Frequency of Code Blue, and Causes of Mortality

Desaturation (88.7\%) was the most common anesthesia-related complication, whereas respiratory arrest was the most common (32\%) cause of mortality. "Code blue" in the endoscopy unit was observed once a year (56.7\%) and once a month (12.8\%). In addition, $17.7 \%(n=25)$ of gastroenterology specialists encountered complications that resulted in mortality.

\section{Relationship Between Anesthesia Team and Sedation Practices}

A significant positive correlation was found among centers where anesthesia technicians are present during sedation practices and general anesthesia and deep sedation, midazolam, ketamine, fentanyl and

Table 2. Anesthesia method and anesthetic agents, endoscopic procedure, and patient characteristics

\begin{tabular}{|l|l|}
\hline Frequency of sedation use & $\mathbf{n}(\%)$ \\
\hline All patients & $33(23.4)$ \\
\hline Usually & $38(27)$ \\
\hline Often & $55(39)$ \\
\hline Rarely & $15(10.6)$ \\
\hline Patients deemed unfit for sedation & \\
\hline Patients who refuse sedation & $86(61)$ \\
\hline $\begin{array}{l}\text { Patients with additional diseases (cardiac, pulmonary, renal } \\
\text { etc.) }\end{array}$ & $74(52.5)$ \\
\hline Elderly patients & $28(19.9)$ \\
\hline Patients without anxiety & $6(4.3)$ \\
\hline Other causes & $6(4.3)$ \\
\hline Anesthesia methods & $\mathbf{n}(\%)$ \\
\hline Conscious sedation & $107(75.9)$ \\
\hline Local pharyngeal anesthesia & $92(65.2)$ \\
\hline Deep sedation & $103(73)$ \\
\hline General anesthesia & $20(14.2)$ \\
\hline Anesthetic agent & \\
\hline Midazolam & $130(92.2)$ \\
\hline Propofol & $106(75.2)$ \\
\hline Fentanyl & $33(23.4)$ \\
\hline Ketamine & $14(9.9)$ \\
\hline Remifentanyl & $8(5.7)$ \\
\hline Others & $10(7.1)$ \\
\hline
\end{tabular}

remifentanil use, electrocardiogram (ECG), non-invasive blood pressure, and bispectral index monitoring.

A significant positi ve correlation was found among centers where anesthesia technicians are present during sedation practices and general anesthesia, use of propofol and fentanyl, and use of ECG and non-invasive blood pressure monitoring.

A significant positive relationship was found among centers where nurses are present during sedation practices and conscious sedation.

Those with a code blue frequency of once yearly had a significantly lower frequency of having an anesthesiologist in their team. Those

Table 3. Endoscopy unit, monitoring methods, oxygen administration, sedation recovery area, pre-anesthetic evaluation and consent forms

\begin{tabular}{|c|c|}
\hline Equipment & n (\%) \\
\hline Oxygen supply & $141(100)$ \\
\hline Aspirator & $139(98)$ \\
\hline Emergency trolley & $129(91.5)$ \\
\hline Monitor & $128(90.8)$ \\
\hline Defibrillator & $92(65.2)$ \\
\hline Appropriate area with sufficient width & $72(51.1)$ \\
\hline Anesthesia device & $61(43.3)$ \\
\hline Perfusor & $22(15.6)$ \\
\hline Monitoring method & $\mathrm{n}(\%)$ \\
\hline Peripheral oxygen saturation & $137(97.2)$ \\
\hline Non-invasive blood pressure & $68(48.2)$ \\
\hline ECG & $64(45.4)$ \\
\hline BIS monitoring & $8(5.7)$ \\
\hline Capnography & $0(0)$ \\
\hline Nasal oxygen administration & $\mathrm{n}(\%)$ \\
\hline All patients & $76(53.9)$ \\
\hline Only desaturated patients & $46(32.6)$ \\
\hline Only high-risk patients & $32(22.7)$ \\
\hline None & $3(2.1)$ \\
\hline Sedation recovery area & $\mathrm{n}(\%)$ \\
\hline In recovery unit & $81(57.4)$ \\
\hline At the operation site & $54(38.3)$ \\
\hline In the waiting room & $11(7.8)$ \\
\hline In the department & $7(5)$ \\
\hline Pre-anesthetic examination & n (\%) \\
\hline Yes & $93(66.0)$ \\
\hline No & $48(34.0)$ \\
\hline Anesthesia consent forms & n (\%) \\
\hline $\begin{array}{l}\text { We have written consent forms, and } \\
\text { I routinely ask patients to complete and sign them. }\end{array}$ & $123(87.2)$ \\
\hline $\begin{array}{l}\text { We have written consent forms, } \\
\text { but I do not ask all patients to complete and sign them. }\end{array}$ & $17(12.1)$ \\
\hline $\begin{array}{l}\text { We do not have written consent forms, } \\
\text { and I do not receive written consent from patients. }\end{array}$ & $1(0.7)$ \\
\hline
\end{tabular}


with a code blue frequency of once monthly and once yearly had a significantly higher frequency of having a nurse in their team.

\section{Discussion}

Based on our literature review, we think that our study is the first national survey to evaluate sedation practices in endoscopy units in Turkey. With a response rate of 18.95\% (141/744), the results of our study were similar to those of Germany (17\%), Korea (22.7\%), USA (27\%), and Portugal (26\%) according to gastroenterologists' response rates to survey request. However, it was lower than those of Spain (65\%), Switzerland (78\%), Italy (41\%), and Greece (40\%) (6-8,11,12,14-17).

In our study, sedation practices were applied in the majority of the endoscopy units in Turkey; however, sedation was applied to $72 \%$ of the patients (33\% for each patient, 39\% frequently). This rate was lower than that in the USA (98\%) and Germany (82\% for gastroscopy and 91\% for

\begin{tabular}{|l|l|}
\hline Table 4. Anesthesia team members & \\
\hline Anesthesia team & $\mathbf{n}(\%)$ \\
\hline Anesthesiologist & $75(53.2)$ \\
\hline Anesthesia technician & $85(60.3)$ \\
\hline Nurse & $81(57.4)$ \\
\hline Other & $24(17)$ \\
\hline Who do you think the anesthesia team should consist of? & $\mathbf{n}(\%)$ \\
\hline Anesthesiologist & $122(86.5)$ \\
\hline Anesthesia technician & $115(81.6)$ \\
\hline Nurse & $70(49.6)$ \\
\hline Other & $3(2.1)$ \\
\hline
\end{tabular}

Table 5. Anesthesia-related complications, frequency of code blue, and causes of mortality

\begin{tabular}{|l|l|}
\hline Complications & $\mathbf{n}(\mathbf{\%})$ \\
\hline Desaturation & $125(88.7)$ \\
\hline Bradyarrhythmias & $29(20.6)$ \\
\hline Hypotension & $25(17.7)$ \\
\hline Nausea/vomiting & $13(9.2)$ \\
\hline Other & $2(1.4)$ \\
\hline Frequency of code blue & $\mathbf{n}(\%)$ \\
\hline Once a year & $80(56.7)$ \\
\hline Once a month & $18(12.8)$ \\
\hline Once a week & $2(1.4)$ \\
\hline Other & $41(29.1)$ \\
\hline Cause of mortality (n=25) & $\mathbf{n}(\%)$ \\
\hline Respiratory arrest & $8(32)$ \\
\hline Cardiac-related causes & $6(24)$ \\
\hline Anaphylactic shock & $4(16)$ \\
\hline Hypotension & $2(8)$ \\
\hline Bleeding varicose & $2(8)$ \\
\hline Anesthesia & $1(4)$ \\
\hline Cerebrovascular event & $1(4)$ \\
\hline Pacemaker asystole & $1(4)$ \\
\hline & \\
\hline
\end{tabular}

colonoscopy), similar to that in Greece $(68.2 \%, 2015)(74.8 \%, 2018)$, and higher than those in China (48.3\%) and India (36.8\%) (14,18-21). Available studies have shown that the sedation rate mainly differs according to the hospital type and economic conditions $(12,18)$. In addition to these factors, we think that restricted time because of the high number of patients can be included as one of the reasons that negatively affect our sedation rate.

In India, a study reported therapeutic procedures, high-risk procedures, and patient request as patient selection criteria for sedation (13). In our study, 86 (61\%) patients who refused anesthesia and 74 (52.5\%) who had other diseases (cardiac, pulmonary, renal, etc.) were included in the patient group in which gastroenterology specialists did not prefer to use sedation. Both studies did not consider advanced age an important criterion for deciding on sedation. In our study, advanced age was another reason for not preferring sedation with a rate of $28 \%$, which was consistent with the literature.

Many studies have investigated anesthetic agents used in endoscopic sedation. These studies show significant differences in drug preference according to the person responsible for the use of sedation. It is universally accepted that midazolam can be used without an anesthesiologist. However, the use of propofol without an anesthesiologist can vary between $0 \%$ and $100 \%$ depending on the country $(7,8,11,15,16)$. Propofol has advantages in terms of shorter eye-opening and postanesthetic recovery time and higher patient and doctor satisfaction (1,22). However, its potential to cause hemodynamic and respiratory depression is a matter of concern (19). The most commonly used sedative and analgesic agents are propofol (61\%) and fentanyl (36.3\%) in China, midazolam (52.6\%) in India, propofol (24\%) in Germany, propofol alone or in combination with midazolam in Korea and Portugal (55.6\%), and propofol in Greece (30.8\%) (18,19-24). These differences can be explained by medical and legal concerns. Some of these countries allow non-anesthesiologists to perform sedation in gastrointestinal endoscopy. In such cases, sedation is administered by nurses, endoscopists, or other trained personnel. Surveys conducted in the USA, Italy, and Portugal showed that propofol use was almost entirely administered by anesthesiologists, whereas surveys from Germany and Spain showed that propofol was almost entirely administered by non-anesthesiologists $(7,11,12,15,16)$. In our study, the most commonly used anesthetic agents were midazolam (92\%) and propofol (75\%). A higher rate of propofol use compared with the rate of having an anesthesiologist during endoscopy (53.2\%) reflects the use of propofol by gastroenterology specialists. While the American Society for Gastrointestinal Endoscopy and European Society of Gastrointestinal Endoscopy have guidelines for sedation in gastrointestinal endoscopy, unfortunately, we have not found any domestic guidelines published by a relevant association, which leads to applications according to personal preferences in different regions of the country $(23,24)$.

According to our survey results, the most common monitoring method was monitoring of peripheral oxygen saturation $\left(\mathrm{SpO}_{2}, 97 \%\right)$, consistent with those in several other countries $(7,11,12,17,25)$. Despite its widespread use, the $\mathrm{SpO}_{2}$ can show higher oxygen levels than the arterial oxygen value, even if severe alveolar hypoventilation occurs (20). Continuous capnographic monitoring is recommended by the American Society of Anesthesiologists (ASA) to evaluate the adequacy of ventilation 
Table 6. Relationship between the anesthesia team and sedation practices

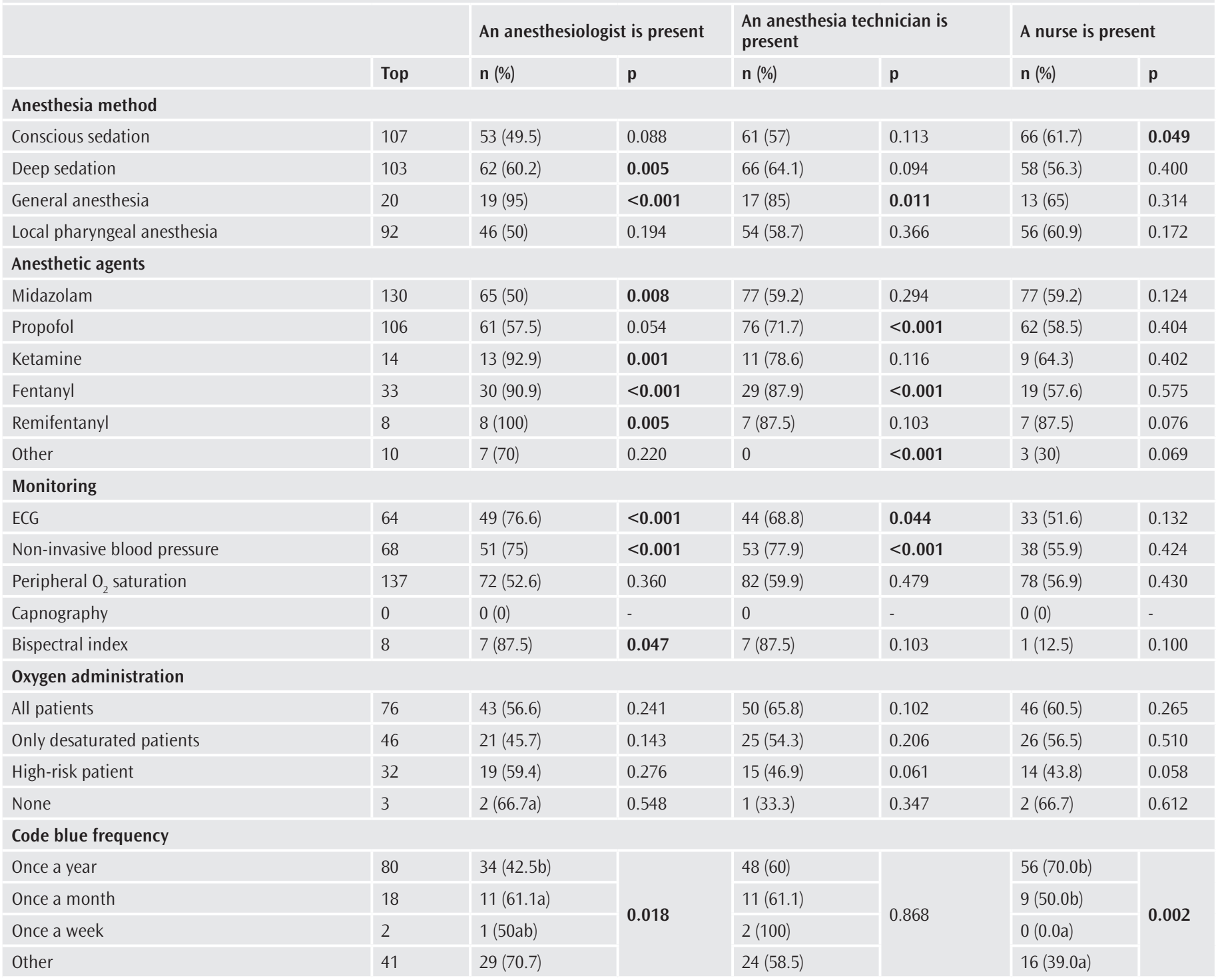

(21). However, capnographic monitoring was not performed in any center included in our survey. We believe that future guidelines will help increase its implementation with the conveyance of the importance of capnographic monitoring.

In our study, blood pressure and ECG monitoring rates were $45-48 \%$ in the follow-up of cardiac effects. Blood pressure and ECG follow-up were performed in India (42.1\%), Italy (30\%), and China $79.3 \%$ and $76.5 \%$, respectively) $(11,13,25)$. We believe that low ECG rates result from the fact that ECG monitoring requires a specific perspective and assistant health personnel trained in this regard (device setup and electrode placement). A review of competent association guides in these fields demonstrates that ECG is considered among basic monitoring methods. Despite these guidelines, a low rate of ECG monitoring applied by practitioners may also cause medicolegal problems.

In our survey, supplemental nasal oxygen administration was routinely preferred (53\%). The use of supplemental oxygen has been associated with a reduced incidence of hypoxemia during moderate sedation (2629). It is also recommended by the ASA (19). Continuous nasal oxygen is applied in China (95.5\%), whereas nasal oxygen is administered in Korea (52.6\%), Italy (39.3\%), and USA $(72.7 \%)(7,11,17,25)$. This rate was $76 \%$ in the present study.

We found that necessary emergency equipment such as oxygen supply (100\%), aspirator (98\%), emergency vehicle (91.5\%), and monitor (90.8\%) were provided at a high rate, whereas the rate of defibrillator availability (65.2\%) was relatively lower. These rates were higher than those of China and Greece and similar to India $(13,25,30)$. Generally, one should watch out for potentially fatal side effects of sedation and consider safety parameters. Emergency equipment should be provided to ensure patient safety.

A preoperative pre-anesthetic evaluation was performed by $66 \%$ of the respondents, whereas $34 \%$ did not perform a pre-anesthetic evaluation. A survey conducted in Korea with a similar rate (38.3\%) found that the practitioners never used the ASA classification for preprocedural evaluation or they seldom used it (17). High ASA classification, a definite risk factor for complications, is now recommended as an important quality indicator for all gastrointestinal endoscopic procedures. 
We found that anesthesia technicians (60.3\%) constituted the majority of the anesthesia team, followed by nurses (57.4\%) and anesthesiologists (53.2\%). However, when asked about the preferences of gastroenterology specialists, the majority (86.5\%) preferred an anesthesiologist. In another survey study, with regard to preference for sedation to be administered by an anesthesiologist for endoscopic procedures, the majority of the respondents (68\% versus 32\%) stated that they would prefer the presence of an anesthesiologist (8). The high demand for the administration of sedation by an anesthesiologist was associated with concerns regarding medicolegal and patient comfort.

The most common complication during sedation was desaturation (88.7\%), and code blue occurred once yearly at $56.7 \%$ and once monthly at $12.8 \%$. Moreover, $17.7 \%(n=25)$ of the gastroenterology specialists encountered complications that resulted in mortality. Among the causes of mortality, respiratory arrest had a rate of $32 \%$. These results highlight the importance of close monitoring of vital signs and airway management during sedation. Necessary interventions should be performed when required. The risks for patients and physicians increase when ambient light is reduced during endoscopy procedures, the endoscopist concentrates on the procedure, and a nurse working with endoscopist's directives is present. The results of our survey also reveal the importance of such awareness.

\section{Study Limitations}

This study provides an insight into current national approaches toward sedation use in gastrointestinal endoscopy. However, this study has some considerable limitations. First, only $18.95 \%$ of the associate members responded to our survey; therefore, the results may not fully reflect the overall situation in Turkey. Second, a significant majority (53\%) of the gastroenterologists responding to our survey worked in university hospitals, and a substantial portion consisted of young physicians (3049 years old, 78.7\%). Such sample heterogeneity can be considered a limiting factor in adapting our results to the whole country. Moreover, this survey type bears several well-known systematic biases, such as recall bias and self-report bias.

\section{Conclusion}

We believe that our study provides an insight into current sedation practices in endoscopy units where procedural complexity is experienced. We observed that gastroenterology specialists prefer a competent anesthetist to administer sedation during the procedure. We also determined that those without such an opportunity acted based on their personal experiences on how to proceed. We believe that it is necessary to prepare guidelines on sedation use in endoscopy units to assist care providers and health managers in providing quality service.

Ethics Committee Approval: Ethical approval for the study was obtained from Bezmialem Vakıf University Faculty of Medicine Clinical Research Ethics Committee (approval number: 21/30, date: 18.11.2015).

Informed Consent: Informed consent wasn't obtained.

Peer-review: Externally peer-reviewed.
Authorship Contributions: Concept - H.D.; Design - F.Y.I.; Data Collection or Processing - F.Y.I., H.D., Y.Y., Y.K.; Analysis or Interpretation - F.Y.I., H.D., Y.Y., Y.K.; Literature Search - F.Y.I.; Writing - F.Y.I.

Conflict of Interest: No conflict of interest was declared by the authors.

Financial Disclosure: The authors declared that this study received no financial support.

\section{References}

1. McQuaid KR, Laine L. A systematic review and meta-analysis of randomized, controlled trials of moderate sedation for routine endoscopic procedures. Gastrointest Endosc 2008; 67: 910-23.

2. Cohen LB, Delegge MH, Aisenberg J, Brill JV, Inadomi JM, Kochman ML, et al. AGA Institute review of endoscopic sedation. Gastroenterology 2007; 133: 675-701.

3. Training Comitee, American society for gastrointestinal endoscopy. Training guideline for use of propofol in gastrointestinal endoscopy. Gastrointest Endosc 2004; 60: 167-72.

4. Perel A. Non-anaesthesiologists should not be allowed to administer propofol for procedural sedation: a Consensus Statement of 21 European National Societies of Anaesthesia. Eur J Anaesthesiol 2011; 28: 580-4.

5. Pelosi P, Board of the European Society of Anaesthesiology. Retraction of endorsement: European Society of Gastrointestinal Endoscopy, European Society of Gastroenterology and Endoscopy Nurses and Associates and the European Society of Anaesthesiology Guideline: non-anaesthesiologist administration of propofol for gastrointestinal endoscopy. Eur J Anaesthesiol 2012; 29: 208.

6. Heuss LT, Froehlich F, Beglinger C. Changing patterns of sedation and monitoring practice during endoscopy: results of a nationwide survey in Switzerland. Endoscopy 2005; 37: 161-6.

7. Cohen LB, Wecsler JS, Gaetano JN, Benson AA, Miller KM, Durkalski V, et al. Endoscopic sedation in the United States: results from a nationwide survey. Am J Gastroenterol 2006; 101: 967-74.

8. Paspatis GA, Manolaraki MM, Tribonias G, Theodoropoulou A, Vardas E, Konstantinidis K, et al. Endoscopic sedation in Greece: results from a nationwide survey for the Hellenic Foundation of gastroenterology and nutrition. Dig Liver Dis 2009; 41: 807-11.

9. Riphaus A, Rabofski M, Wehrmann T. Endoscopic sedation and monitoring practice in Germany: results from the first nationwide survey. Z Gastroenterol 2010; 48: 392-7.

10. Porostocky P, Chiba N, Colacino P, Sadowski D, Singh H. A survey of sedation practices for colonoscopy in Canada. Can J Gastroenterol 2011; 25: 255-60.

11. Fanti L, Agostoni M, Gemma M, Radaelli F, Conigliaro R, Beretta L, et al. Sedation and monitoring for gastrointestinal endoscopy: a nationwide web survey in Italy. Dig Liver Dis 2011; 43: 726-30.

12. Lucendo AJ, González-Huix F, Tenias JM, Lopez-Roses L, Alonso-Aguirre P, Quintero E, et al. Gastrointestinal endoscopy sedation and monitoring practices in Spain: a nationwide survey in the year 2014. Endoscopy 2015; 47: 383-90

13. Zacharias P, Mathew S, Mathews J, Somu A, Peethambaran M, Prashanth M, et al. Sedation practices in gastrointestinal endoscopy-A survey from southern India. Indian J Gastroenterol 2018; 37: 164-8.

14. Conigliaro R, Rossi A, Italian Society of Digestive Endoscopy (SIED) Sedation Commission. Implementation of sedation guidelines in clinical practice in Italy: results of a prospective longitudinal multicenter study. Endoscopy 2006; 38: $1137-43$.

15. Riphaus A, Geist F, Wehrmann T. Endoscopic sedation and monitoring practice in Germany: re-evaluation from the first nationwide survey 3 years after the 
implementation of an evidence and consent based national guideline. Z Gastroenterol 2013; 51: 1082-8.

16. Ferreira AO, Torres J, Dinis-Ribeiro M, Cravo M. Endoscopic sedation and monitoring practices in Portugal: a nationwide web-based survey. Eur J Gastroenterol Hepatol 2015; 27: 265-70.

17. Lee CK, Dong SH, Kim ES, Moon SH, Park HJ, Yang DH, et al. Korean Society of Gastrointestinal Endoscopy Task Force on Endoscopic Sedation. Room for Quality Improvement in Endoscopist-Directed Sedation: Results from the First Nationwide Survey in Korea. Gut Liver 2016; 10: 83-94.

18. Wang HL, Ye F, Liao WF, Xia B, Zheng GR. Unsedated versus sedated gastrointestinal endoscopy: a questionnaire investigation in Wuhan, central China. J Huazhong Univ Sci Technolog Med Sci 2013; 33: 857-61.

19. Standards of Practice Committee of the American Society for Gastrointestinal Endoscopy, Lichtenstein DR, Jagannath S, Baron TH, Anderson MA, BAnerjee $\mathrm{S}$, et al. Sedation and anesthesia in Gl endoscopy. Gastrointest Endosc 2008; 68: 815-26.

20. Fu ES, Downs JB, Schweiger JW, Miguel RV, Smith RA. Supplemental oxygen impairs detection of hypoventilation by pulse. Chest 2004; 126: 1552-8.

21. Practice guidelines for moderate procedural sedation and analgesia 2018: a report by the american society of anaesthesiologists task force on moderate procedural sedation and analgesia, the american association of oral and maxillofacial surgeons, american college of radiology, american dental association, american society of dentist anaesthesiologists, and society of interventional radiology. Anaesthesiology 2018; 128: 437-79.

22. Zhang W, Zhu Z, Zheng Y. Effect and safety of propofol for sedation during colonoscopy: A meta-analysis. J Clin Anesth 2018; 51: 10-8.

\section{Appendix A. Survey form}

Attitudes and behaviors of gastroenterology specialists toward sedation practices in endoscopy units in turkey: is anesthesia mandatory?

\section{Dear Gastroenterology Specialist:}

Our survey invites all gastroenterology specialists in Turkey to respond questions regarding sedation practices you apply in endoscopy units. Through this survey, we aim to determine national sedation practices and experiences and preferences of gastroenterology specialists in endoscopy units.

Thank you for participating in our 10-minute survey.

- Age:

- Gender: Female....... Male........

- Length of experience as a gastroenterology specialist:

- What type of hospital are you working in? University ...... Training and Research ....... State ...... Private .......

- Province:

- Number of beds in the institution:
23. https://www.esge.com/assets/downloads/pdfs/guidelines/2010_non_ anesthesiologist_admin_propofol_gi_endo.pdf

24. https://www.asge.org/docs/defaultsource/education/practice_guidelines/ piis0016510717321119.pdf?sfvrsn=50a3aa50_4

25. Zhou S, Zhu Z, Dai W, Qi S, Tian W, Zhang Y, et al. National survey on sedation for gastrointestinal endoscopy in 2758 Chinese hospitals. Br J Anaesth 2021; 127: 56-64.

26. Lin Y, Zhang X, Li L, Wei M, Zhao B, Wang X, et al. High-flow nasal cannula oxygen therapy and hypoxia during gastroscopy with propofol sedation: a randomized multicenter clinical trial. Gastrointest Endosc 2019; 90: 591-601.

27. Deitch K, Chudnofsky CR, Dominici P. The utility of supplemental oxygen during emergency department procedural sedation and analgesia with midazolam and fentanyl: a randomized, controlled trial. Ann Emerg Med 2007; 49: 1-8.

28. Deitch K, Chudnofsky CR, Dominici P, Latta D, Salamanca Y. The utility of high-flow oxygen during emergency department procedural sedation and analgesia with propofol: a randomized, controlled trial. Ann Emerg Med. 2011; 58: 360-4.

29. Rozario L, Sloper D, Sheridan MJ. Supplemental oxygen during moderate sedation and the occurrence of clinically significant desaturation during endoscopic procedures. Gastroenterol Nurs 2008; 31: 281-5.

30. Protopapas AA, Stournaras E, Neokosmidis G, Stogiannou D, Filippidis A, Protopapas AN. Endoscopic sedation practices of Greek gastroenterologists: a nationwide survey. Ann Gastroenterol 2020; 4: 366-73.

1. In your endoscopy unit, do you use sedation for patients during diagnostic and/or therapeutic procedures, interventions, and operations?

a. Yes

b. No

\section{If yes, how often do use it?}
a. Every time
b. Usually
c. Frequently
d. Rarely

3. Is there a specific patient group for which you do not prefer to use sedation?

a. Patients who refuse sedation

b. Elderly patients

C. Patients without anxiety

d. Patients with other diseases (cardiac, pulmonary, renal etc.)

e. Other $(\ldots \ldots \ldots \ldots \ldots \ldots)$

4. In which procedures and interventions is sedation used in the endoscopy unit?

a. Gastroscopy

b. Colonoscopy

c. EUS 

d. ERCP
e. ESD
f. Other (....

5. Which sedation method or methods are used in the endoscopy unit?
a. Conscious sedation
b. Deep sedation
c. General anesthesia
d. Local pharyngeal anesthesia
e. Other $(\ldots \ldots \ldots \ldots \ldots . . . .$.

6. Which agent or agents do you prefer the most for patients undergoing sedoanalgesia in the endoscopy unit?
a. Midazolam
b. Propofol
c. Ketamine
d. Etomidate
e. Thiopental
f. Fentanyl
g. Alfentanyl
h. Remifentanyl
i. Other $(\ldots \ldots \ldots \ldots \ldots . . . . .$.

7. What facilities and equipment are available in the endoscopy unit where you apply sedation?
a. Oxygen supply
b. Aspirator
c. Anesthesia device
d. Defibrillator
e. Monitor
f. Perfusor
g. Emergency trolley
h. Appropriate area with sufficient width

8. Which monitoring methods do you use as part of your sedation practices in the endoscopy unit?
a. ECG
b. Non-invasive blood pressure
c. Invasive arterial monitoring
d. Peripheral oxygen saturation
e. Capnography
f. TOF monitoring
g. Arterial blood gas analysis
h. BIS monitoring
i. Other $(. .$.

9. Do you apply nasal cannula oxygenation to all patients in the endoscopy unit?
a. All patients
b. Only desaturated patients
c. Only high-risk patients
d. None

10. Who among the following is included in the anesthesia team of the endoscopy unit of your current institution?
a. Anesthesiologist
b. Anesthetic technician
c. Nurse
d. Other (....

11. Who do you think the anesthesia team should consist of?
a. Anesthesiologist
b. Anesthetic technician
c. Nurse
d. Other

12. Do you perform pre-anesthesia examination by listing patients to be sedated in the endoscopy unit?
a. Yes
b. No

13. Do you receive written consent from patients you sedate in the endoscopy unit or from their legal guardians for those who are unable to give consent, and do you have written informed consent forms?

a. We have written consent forms, and I routinely ask patients to complete and sign them.

b. We have written consent forms, but I do not ask all patients to complete and sign them.

c. We do not have written consent forms, and I do not ask patients to sign them.

14. Where do you compile outpatient data who received sedation in the endoscopy unit?
a. Operation site
b. Department
C. Waiting room
d. Recovery unit
e. Other (.....

15. What is the most common intraoperative complication you encounter in the endoscopy unit?
a. Desaturation
b. Hypotension
c. Bradyarrhythmias
d. Nausea/vomiting
e. Other $(\ldots \ldots \ldots \ldots \ldots . . . .$. 
16. What is the frequency of code blue in the endoscopy unit?
a. Everyday
b. Once a week
c. Once every 2 weeks
d. Once a month
e. Once a year
f. Other $(\ldots \ldots \ldots . .$.

18. For those who responded yes to question 18, what was the cause(s) of mortality?

$(\ldots \ldots \ldots \ldots \ldots \ldots \ldots \ldots \ldots \ldots \ldots \ldots \ldots \ldots \ldots \ldots \ldots \ldots \ldots \ldots \ldots \ldots \ldots \ldots \ldots \ldots \ldots \ldots \ldots \ldots \ldots \ldots \ldots \ldots$
THANK YOU
EUS: Endoscopic ultrasound, ERCP: endoscopic retrograde cholangiopancreatography, ESD:
endoscopic submucosal dissection, BIS: bispectral index, TOF: train-of-four

\section{Have you encountered anesthesia-related complications resulting} in mortality in the endoscopy unit?
a. Yes
b. No 